Hydrol. Earth Syst. Sci., 15, 3431-3446, 2011

www.hydrol-earth-syst-sci.net/15/3431/2011/

doi:10.5194/hess-15-3431-2011

(C) Author(s) 2011. CC Attribution 3.0 License.

\title{
Simple physics-based models of compensatory plant water uptake: concepts and eco-hydrological consequences
}

\author{
N. J. Jarvis \\ Department of Soil \& Environment, SLU, P.O. Box 7014, 75007 Uppsala, Sweden \\ Received: 20 June 2011 - Published in Hydrol. Earth Syst. Sci. Discuss.: 12 July 2011 \\ Revised: 27 October 2011 - Accepted: 28 October 2011 - Published: 16 November 2011
}

\begin{abstract}
Many land surface schemes and simulation models of plant growth designed for practical use employ simple empirical sub-models of root water uptake that cannot adequately reflect the critical role water uptake from sparsely rooted deep subsoil plays in meeting atmospheric transpiration demand in water-limited environments, especially in the presence of shallow groundwater. A failure to account for this so-called "compensatory" water uptake may have serious consequences for both local and global modeling of water and energy fluxes, carbon balances and climate. Some purely empirical compensatory root water uptake models have been proposed, but they are of limited use in global modeling exercises since their parameters cannot be related to measurable soil and vegetation properties. A parsimonious physicsbased model of uptake compensation has been developed that requires no more parameters than empirical approaches. This model is described and some aspects of its behavior are illustrated with the help of example simulations. These analyses demonstrate that hydraulic lift can be considered as an extreme form of compensation and that the degree of compensation is principally a function of soil capillarity and the ratio of total effective root length to potential transpiration. Thus, uptake compensation increases as root to leaf area ratios increase, since potential transpiration depends on leaf area. Results of "scenario" simulations for two case studies, one at the local scale (riparian vegetation growing above shallow water tables in seasonally dry or arid climates) and one at a global scale (water balances across an aridity gradient in the continental USA), are presented to illustrate biases
\end{abstract}

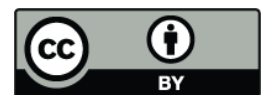

Correspondence to: N. J. Jarvis (nicholas.jarvis@slu.se) in model predictions that arise when water uptake compensation is neglected. In the first case, it is shown that only a compensated model can match the strong relationships between water table depth and leaf area and transpiration observed in riparian forest ecosystems, where sparse roots in the capillary fringe contribute a significant proportion of the water uptake during extended dry periods. The results of the second case study suggest that uncompensated models may give biased estimates of long-term evapotranspiration at the continental scale. In the example presented here, the uncompensated model underestimated total evapotranspiration by $5-7 \%$ in climates of intermediate aridity, while the ratio of transpiration to evaporation was also smaller than for the compensated model, especially in arid climates. It is concluded that the parsimonious physics-based model concepts described here may be useful in the context of eco-hydrological modeling at local, regional and global scales.

\section{Introduction}

Root water uptake by plants is one of the major components of the terrestrial water balance and a critical process controlling energy exchange between the land surface and the atmosphere and plant growth. Sub-models of root water uptake are therefore sensitive and important building blocks in ecohydrological models that simulate terrestrial water, energy and carbon balances to support, for example, crop growth or global climate models (Wang and Smith, 2004; Seneviratne et al., 2010). One especially important and difficult task for root water uptake models is to reflect the dynamic response of plant uptake to water stress, in which uptake

Published by Copernicus Publications on behalf of the European Geosciences Union. 
increases from sparsely rooted but well-watered parts of the root zone to compensate for stress in other parts. This compensatory increase of water uptake from soil zones that are still well-watered following drying of more densely rooted layers has been repeatedly and convincingly documented for several decades (e.g. Arya et al., 1975a, b; Nnyamah and Black, 1977; Green and Clothier, 1995). Indeed, water uptake from deep subsoil has been shown to be critical in meeting atmospheric transpiration demand in water-limited environments (e.g. Jipp et al., 1998; Oliveira et al., 2005), especially where roots can reach shallow groundwater (Zhang et al., 1999; Zencich et al., 2002; Lamontagne et al., 2005; Cleverly et al., 2006; Gazal et al., 2006; Paço et al., 2009).

The physical basis of compensatory uptake can be explained by an Ohm's law analogue to water flow in the soilplant-atmosphere continuum. As soil dries, plant water potentials will also decrease, but the spatially (and especially vertically) distributed nature of the root system means that the hydraulic gradient between the canopy and soil layers that are still wet increases to compensate for the increased resistance to flow encountered from dry soil zones, so that transpiration can be maintained at the potential rate demanded by the atmosphere. This is analogous to the "constant rate" stage of soil evaporation, whereby the reduction in hydraulic conductivity in the drying surface soil is compensated by the increasing hydraulic gradient towards the soil surface. However, at air-dryness of the surface, the gradient cannot further increase and the "falling rate" stage begins. Analogously, stomata close at a critical leaf water potential (Jarvis, 1976) when the rate of supply of water from the soil root zone falls below the atmospheric demand and the "falling rate" stage for transpiration begins. A corollary of this explanation is that "compensatory uptake" should be implicit in any physics-based model of water uptake. Biological response mechanisms are superimposed on these physical aspects: "plastic" responses of plant rooting patterns to spatial variation in soil wetness are very well documented in annual crops (e.g. Wraith and Wright, 1998). For example, contrasting irrigation practices can significantly alter the root biomass and vertical distribution of roots (e.g. Meyer, et al., 1990; Zuo et al., 2006). Soil drying in the densely rooted topsoil can induce an increased allocation of assimilates to roots, a faster root penetration rate into the subsoil, and increased root growth in deeper, wetter soil layers at the expense of dry soil zones (Sharp and Davies, 1985; Meyer et al., 1990; Engels et al., 1994; Kager et al., 2004). These plastic root responses can be both rapid, occurring on a timescale of weeks or even days (Klepper et al., 1973) and are also reversible (Engels et al., 1994). The potential for such plastic responses depends on the degree to which the plant can adjust the allocation of assimilates, which is determined by growth stage (Carmi et al., 1993), and can also vary significantly between crop species (Benjamin and Nielsen, 2006). Perennial plants can also show significant root plasticity in response to vertical variation in soil water status at seasonal time scales (e.g. Wan et al., 2002; Peek et al., 2006) and also as a result of inter-species competition for scarce resources (e.g. Celette et al., 2008).

One important unresolved challenge is to develop root water uptake models which are both relatively parsimonious with respect to data requirements and can also capture the complexity of the bio-physical response mechanisms underlying compensatory uptake in a realistic way (Doussin, 2003; Wang and Smith, 2004). "Root architecture" models linked to soil water flow models (e.g. Clausnitzer and Hopmans, 1994; Somma et al., 1998; Javaux et al., 2008; Draye et al., 2010) can provide extremely useful insights into the processes, but are too complex for routine use in large-scale modeling applications. Conversely, many crop growth models and land surface schemes include advanced mechanistic treatments of above-ground processes, but tend to oversimplify one or more aspects of root water uptake and cannot simulate compensation mechanisms. The failure to account for compensatory water uptake and the related phenomenon of hydraulic lift from deep subsoil (Dawson, 1993; Caldwell et al., 1998) may have serious consequences for both sitespecific applications of plant growth and eco-hydrological models and the global modeling of water, energy and carbon balances and climate (Desborough, 1997; Zeng et al., 1998; Kleidon and Heimann, 1998; Lee et al., 2005; Teuling et al., 2006a, b; Seneviratne et al., 2010), although the magnitude of these errors is not yet well understood.

Several simple "macroscopic" models have been proposed that can account for compensatory uptake. Empirical approaches have been proposed that have been incorporated into some widely-used crop growth models and land surface schemes and found to improve predictions of soil water contents compared to the case without compensatory uptake (e.g. Cabelguenne and Debaeke, 1998; Braud et al., 2005; Varado et al., 2006; Bodner et al., 2007; Lawrence and Chase, 2009; El Maayar et al., 2009; Yadav et al., 2009). A simple macroscopic physics-based model of compensatory uptake was recently proposed (de Jong van Lier et al., 2008; Jarvis, 2010) that requires no more parameters than these empirical approaches. This is a significant advantage, especially since its parameters can also be related to measurable properties of the soil and vegetation. This helps clarify the physical basis of compensation and may also allow us to have more confidence in using it to make "blind" predictions at large scales. In this paper, some aspects of the behaviour of this parsimonious physics-based macroscopic approach to modeling compensatory root water uptake are explored in example simulations. Two case studies are then presented that illustrate the potential advantages of the approach as well as the consequences of failing to account for water uptake compensation, one at the local scale (trees and shrubs growing in riparian areas in arid climates that avoid drought stress by exploiting shallow groundwater) and one at a continental scale (simulated water balances for grassland vegetation across an aridity gradient in the USA). 


\section{The Model}

\subsection{Theory and concepts}

From an upscaling analysis of the microscopic flow equation (Darcy's law) of radial water flow to a single root, de Jong van Lier et al. (2008) derived a physics-based macroscopic sink term for root water uptake in which the compensation mechanism is implicit. This model makes use of the matric flux potential, $M\left(\mathrm{~L}^{2} \mathrm{~T}^{-1}\right)$ to linearize the highly non-linear (Darcy) flow equation:

$M=\int_{h_{\mathrm{w}}}^{h} K(h) \mathrm{d} h$

where $h$ and $h_{\mathrm{w}}$ are the actual soil water pressure head and the pressure head at permanent wilting point respectively (L) and $K$ is the soil hydraulic conductivity $\left(\mathrm{L} \mathrm{T}^{-1}\right)$. At the microscopic scale, $M$ continuously decreases in the rhizosphere soil towards its value at the root surface, $M_{0}$ (de Jong van Lier et al., 2006; Schröder et al., 2007). Neglecting the influence of varying internal plant resistances and assuming that $M_{0}$ is constant with depth through the root zone, de Jong van Lier et al. (2008) showed that:

$S_{i}=\rho_{i}\left(\bar{M}_{i}-M_{0}\right)$

where $S_{i}$ is a macroscopic "sink" to the soil water flow equation $\left(\mathrm{T}^{-1}\right)$, which accounts for root water uptake in a given soil layer, $i$, in the root zone, $\overline{M_{i}}$ is the value of $M$ at the average water content of the rhizosphere soil and $\rho_{i}\left(\mathrm{~L}^{-2}\right)$ is a composite rooting parameter given by (de Jong van Lier et al., 2008):

$\rho_{i}=\frac{4}{R_{0}^{2}-a^{2} r_{\mathrm{m}(i)}^{2}+2\left(r_{\mathrm{m}(i)}^{2}+R_{0}^{2}\right) \ln \left(a \frac{r_{\mathrm{m}(i)}}{R_{0}}\right)}$

where $R_{0}$ is the root radius, $r_{\mathrm{m}(i)}$ is the half mean distance between roots and $a$ is the distance from the root (normalized to $\left.r_{\mathrm{m}(i)}\right)$ at which the water content is equal to its average value. Numerical analyses showed that of the three parameters, $\rho_{i}$ is most sensitive to $r_{\mathrm{m}(i)}$, and that $a$ is also reasonably constant for soils of contrasting hydraulic properties and so can be fixed at an average value (median $=0.53$; de Jong van Lier et al., 2006, 2008). It can also be noted that $r_{\mathrm{m}(i)}$ is related to the root length density, $R_{\mathrm{LD}(i)}$, by:

$r_{\mathrm{m}(i)}=\sqrt{\frac{1}{\pi R_{\mathrm{LD}(i)}}}$

while the total root length $R_{L}$ is given by $\sum_{i} R_{\mathrm{LD}(i)} \Delta z_{i}$, where $\Delta z_{i}$ is the layer thickness.

Neglecting any water storage changes in the plant, the actual transpiration, $E_{\mathrm{a}}\left(\mathrm{L} \mathrm{T}^{-1}\right)$, is given by:

$E_{\mathrm{a}}=\sum_{i} S_{i} \Delta z_{i}$
From Eq. (2), the maximum possible transpiration rate, $E_{\max }$ $\left(\mathrm{L} \mathrm{T}^{-1}\right)$ is attained when $M_{0}=0$, so combining Eqs. (2) and (5) gives:

$E_{\max }=\sum_{i} \rho_{i} \overline{M_{i}} \Delta z_{i}$

The actual transpiration can also be defined as:

$E_{\mathrm{a}}=\min \left(E_{\max }, E_{\mathrm{p}}\right)$

where $E_{\mathrm{p}}$ is the potential transpiration rate, which depends on both atmospheric conditions and canopy properties. If the plants are stressed, $E_{\max }<E_{\mathrm{p}}$ and $E_{\mathrm{a}}=E_{\max }$, so $M_{0}=0$ and $S_{i}=\rho_{i} \overline{M_{i}}$. For unstressed plants, $E_{\max } \geq E_{\mathrm{p}}$ and actual transpiration equals the potential rate. In this case, $M_{0}$ can be obtained by combining Eqs. (2), (5) and (6) and setting $E_{\mathrm{a}}=E_{\mathrm{p}}$. Thus, we have:

$M_{0}=\frac{E_{\max }-E_{\mathrm{p}}}{\sum_{i} \rho_{i} \Delta z_{i}} \quad ; \quad E_{\max } \geq E_{\mathrm{p}}$

$M_{0}=0 \quad ; \quad E_{\max }<E_{\mathrm{p}}$

This model was incorporated into the widely-used soil water balance model SWAP and tested against two long-term data sets of measured soil water contents (de Jong van Lier et al., 2008). The approach gave somewhat better predictions than the empirical Feddes et al. (1978) model which does not consider compensatory uptake. More recently, Faria et al. (2010) and Casaroli et al. (2010) tested the model in experiments with split-compartment lysimeters and pots planted with sorghum and beans. Their results generally validated the overall model concept, but it was shown that $\rho_{i}$ in Eq. (2) should be multiplied by an empirical correction factor (=ca. 0.05) to reduce the effective root length. This may be attributed to heterogeneity of the root distribution, non-negligible plant resistances and the presence of gaps between soil and root. One interesting potential advantage of the physical approach is apparent from a consideration of Eq. (2): the phenomenon of hydraulic lift or re-distribution (Dawson, 1993; Caldwell et al., 1998) can be simulated as a source term to the water flow equation, since $\overline{M_{i}}$ can become smaller than $M_{0}$. However, Faria et al. (2010) noted that this model tended to overestimate the quantities of water released by the roots into the soil in their experiments, probably because internal plant resistances are neglected.

Uptake compensation is only implicit in the physics-based model described by de Jong van Lier et al. (2008) and thus its effects are not at first glance obvious from the equations developed above. However, by expressing the model in dimensionless parameters, the role of compensation and the soil and plant factors that influence it, can be made more explicit. A root parameter $R$, a soil resistance factor $\alpha$, and a composite factor $\omega_{c}$ (comprising parameters controlling the balance between the potential rates of soil supply and atmospheric demand for water) can be defined as (Jarvis, 2010):

$R_{i}=\frac{\rho_{i} \Delta z_{i}}{\sum_{i} \rho_{i} \Delta z_{i}}$ 
$\alpha_{i}=\frac{\overline{M_{i}}}{M_{\max }}$

$\omega_{c}=\frac{E_{\mathrm{p}}}{\left(\sum_{i} \rho_{i} \Delta z_{i}\right) M_{\max }}$

where $M_{\max }$ is the maximum value of $\overline{M_{i}}$ (i.e. at $h=0$ ). Note that in the following analysis, $M_{\max }$ must be assumed constant with depth (i.e. a homogeneous soil with respect to hydraulic properties). Combining Eqs. (9), (10) and (11) with Eq. (6) gives:

$\frac{E_{\max }}{E_{\mathrm{p}}}=\frac{\omega}{\omega_{c}}$

where $\omega(0 \leq \omega \leq 1)$, given by $\sum_{i} R_{i} \alpha_{i}$, termed the weighted stress index by Jarvis (1989), can be seen as an overall measure of the potential water supply rate from the root zone. Equation (12) shows that $\omega=\omega_{c}$ at the onset of stress in the plant. If $\omega_{c}>1$, water stress will occur in the plant regardless of the soil water status. If $\omega_{c}=1$, stress will immediately set in as soon as the soil starts to dry from saturation (i.e. when $\omega$ becomes less than 1). If $\omega_{c}<1, E_{\max }$ can be larger than $E_{\mathrm{p}}$ (depending on the value of $\omega$ ) and actual transpiration can therefore be maintained at the potential rate as the soil dries (see Fig. 1 and Eq. 7). Thus, $\omega_{c}$ can be considered as a "compensation factor" that determines the length of the non-stressed period, i.e. how long actual transpiration can be maintained at the potential rate and thus how far the soil can be dried without plant stress occurring (see Fig. 1). A comparison of compensated $\left(\omega_{c}<1\right)$ and uncompensated $\left(\omega_{c}=1\right)$ models shows that compensation increases total water uptake at any moment in time by a factor $1 / \omega$ in the non-stressed phase and by $1 / \omega_{c}$ when plants are stressed (see Eqs. 7 and 12 and Fig. 1). Note also that the solid line (the compensated model) in Fig. 1 is similar to the type of simple function used in single soil reservoir models to estimate actual transpiration as a function of available soil water. The key difference is that transpiration is here controlled by $\omega$, which depends on the relative vertical distributions of roots and soil water within the root zone, something which single reservoir models cannot account for.

Substituting Eqs. (6) and (8) to (11) into Eq. (2), gives the sink term in the de Jong van Lier (2008) model expressed with dimensionless parameters as:

$S_{i}=\frac{E_{\mathrm{p}} R_{i}}{\Delta z_{i}}\left\{\frac{\alpha_{i}}{\omega_{c}}-\left[\max \left(\frac{\omega}{\omega_{c}}, 1\right)-1\right]\right\}$

If $\omega_{c}=1$ (i.e. no compensation), then Eq. (13) reduces to the same functional form as the widely-used empirical model of root water uptake introduced by Feddes et al. (1978):

$S_{i}=\frac{E_{\mathrm{p}}}{\Delta z_{i}} R_{i} \alpha_{i}$

Note, however, that Feddes et al. (1978) defined $\alpha_{i}$ in Eq. (14) as an empirical threshold function of soil water

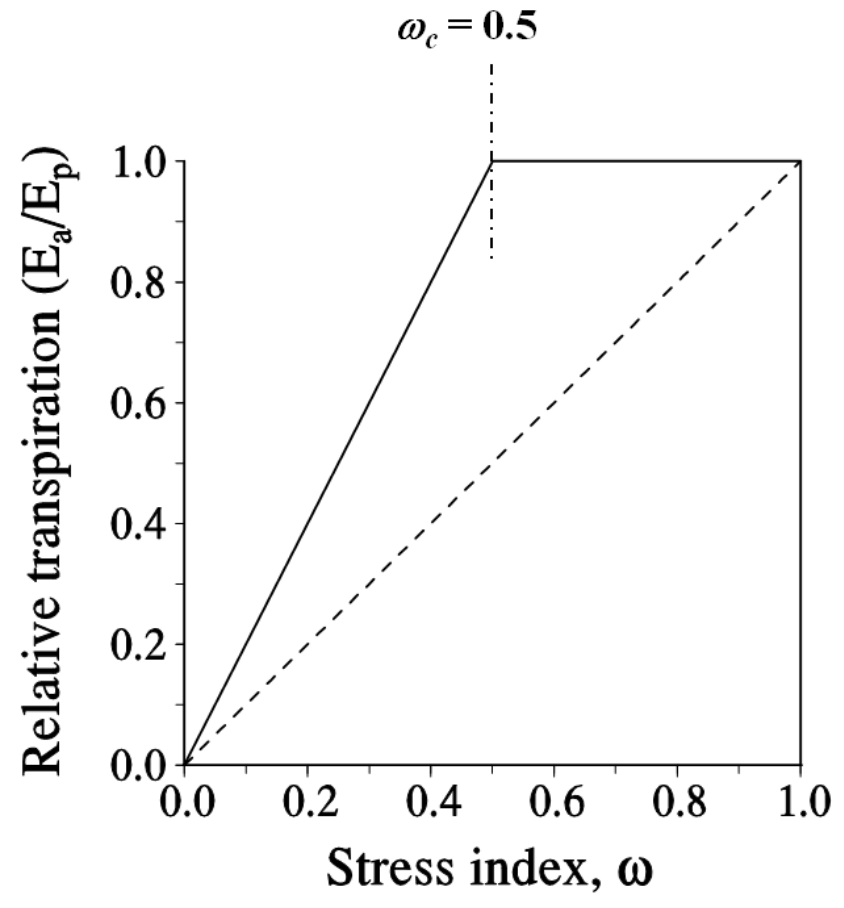

Fig. 1. Water stress, compensation and transpiration predicted by the simple physics-based model. In this example, the solid line illustrates a compensated model with $\omega_{c}=0.5$, while the uncompensated case $\left(\omega_{c}=1\right)$ is illustrated by the dashed line.

pressure head rather than with Eq. (10), with transpiration maintained at the potential rate until a critical pressure head is reached. Some implicit recognition of the compensation mechanism was introduced by making this critical value dependent on $E_{\mathrm{p}}$, such that uptake is maintained at the maximum rate for longer (i.e. to smaller pressure potentials) when $E_{\mathrm{p}}$ is low. A comparison of Eqs. (13) and (14) shows that compensation increases the proportion of water extracted from any given soil layer $\left(=\left(S_{i} \Delta \mathrm{z}_{i}\right) / E_{\mathrm{p}}\right)$ by a factor $1 / \omega_{c}$ if the plants are stressed or by a factor $\frac{1}{\omega_{c}}-\frac{1}{\alpha_{i}}\left(\frac{\omega}{\omega_{c}}-1\right)$ under non-stressed conditions. Thus, compensation only alters the vertical distribution of water uptake under non-stressed conditions, when it favours wetter soil layers over drier. This analysis also clarifies the relationship between water uptake compensation and hydraulic lift or re-distribution. From Eq. (13), it can be seen that hydraulic lift (i.e. negative $S_{i}$ ) can only occur if the following condition is met:

$\alpha_{i}<\omega-\omega_{c}$

Thus, hydraulic re-distribution can only occur under nonstressed conditions $\left(\omega>\omega_{c}\right.$ and $\left.E_{\max }>E_{\mathrm{p}}\right)$. Equation (15) also shows that it should be promoted by small values of $\omega_{c}$ (i.e. strong compensation due to either to low potential transpiration, large total root length or capillary soils, or a combination of these factors, see Eq. 11) and markedly nonuniform root distributions, since during droughts, $\alpha_{i}$ can then 
Table 1. Parameter values used in the simulations.

\begin{tabular}{llll}
\hline Parameter & ${ }^{\mathrm{a}}$ Series 1 & ${ }^{\mathrm{b}}$ Series 2 & ${ }^{\mathrm{c}}$ Series 3 \\
\hline Saturated water content, $\theta_{\mathrm{S}}\left(\mathrm{m}^{3} \mathrm{~m}^{-3}\right)$ & 0.4 & 0.4 & $0.403 / 0.366$ \\
Residual water content, $\theta_{\mathrm{r}}\left(\mathrm{m}^{3} \mathrm{~m}^{-3}\right)$ & 0.0 & 0.0 & $0.025 / 0.025$ \\
Shape parameter, $N$ & 1.2 & $1.2,1.4$ & $1.38 / 1.52$ \\
Shape parameter, $\alpha_{\mathrm{vg}}\left(\mathrm{cm}^{-1}\right)$ & 0.1 & $0.1,0.05$ & $0.038 / 0.043$ \\
Saturated hydraulic conductivity, $K_{\mathrm{S}}\left(\mathrm{cm} \mathrm{h}^{-1}\right)$ & 1.0 & $1.0,2.0$ & $2.5 / 2.9$ \\
Tortuosity factor, $l$ & 0.5 & 0.5 & 0.5 \\
Effective root length $R_{L(\mathrm{eff})}\left(\mathrm{cm} \mathrm{cm}^{-2}\right)$ & $2,10,50$ & 4.0 & 56 \\
Maximum root depth $(\mathrm{cm})$ & 100 & 250 & See Table 3 \\
Root radius, $R_{0}(\mathrm{~cm})$ & 0.02 & 0.02 & 0.01 \\
Root distribution factor, $\beta$ & 0.955 & 0.982 & See Table 3 \\
Priestley-Taylor coefficient, $\alpha_{\mathrm{S}}$ & - & 1.0 & 1.0 \\
Priestley-Taylor coefficient, $\alpha_{\mathrm{max}}$ & - & 1.3 & 1.3 \\
Extinction coefficient, $\sigma$ & - & 0.5 & 0.5 \\
Unstressed stomatal conductance, $g_{\text {sto }}\left(\mathrm{m} \mathrm{s}^{-1}\right)$ & - & 0.002 & 0.005 \\
Julian day of maximum leaf area & - & - & 200 \\
\hline
\end{tabular}

${ }^{\mathrm{a}}$ Loam, Figs. $2-4 ;{ }^{\mathrm{b}}$ Loam (first number) and sand (second number), Figs. $5-7 ;{ }^{\mathrm{c}}$ Coarse soil, topsoil to $30 \mathrm{~cm}$ depth (first number), subsoil (second number), Figs. $8-10$.

become small in relation to the overall soil water status in the root zone, $\omega$.

Jarvis (2010) noted that under stressed conditions $(\omega<$ $\omega_{c}$ ), Eq. (13) is equivalent to the compensatory water uptake model proposed by Jarvis (1989), which can be written as:

$S_{i}=\frac{E_{\mathrm{p}}}{\Delta z_{i}} R_{i} \frac{\alpha_{i}}{\max \left(\omega, \omega_{c}\right)}$

However, a comparison of Eqs. (13) and (16) shows that the two models predict different vertical distributions of water uptake in the soil profile under non-stressed conditions (Jarvis, 2010). The model proposed by Jarvis (1989) assumes that the total water uptake under non-stressed conditions (when $E_{\mathrm{a}}=E_{\mathrm{p}}$ and $\omega>\omega_{c}$ ) is distributed in the root zone proportional to the overall soil stress (i.e. $\left(\alpha_{i} R_{i}\right) / \omega$, see Eq. 16). It is straightforward to derive an expression for $M_{0}$ that equates to this assumption: Eq. (2) can be derived from Eq. (16), with $\alpha_{i}$ and $R_{i}$ defined by Eqs. (9) and (10), when $M_{0}$ is given as (Jarvis, 2010):

$\begin{array}{lll}M_{0}=M\left(1-\frac{E_{\mathrm{p}}}{E_{\max }}\right) ; & E_{\max } \geq E_{\mathrm{p}} \\ M_{0}=0 & ; & E_{\max }<E_{\mathrm{p}}\end{array}$

Thus, the compensatory water uptake model proposed by Jarvis (1989) can be considered as a dimensionless form of the model derived by de Jong van Lier et al. (2008), but with different assumptions concerning $M_{0}$ (contrast Eqs. 8 and 17). Another difference is that Jarvis (1989) treated the compensation factor $\omega_{c}$ as an empirical constant subject to calibration. However, the analysis here shows that, for any given soil and climate, the degree of uptake compensation should depend on many plant properties that are in principle measurable, including the total root length and root radius and also above-ground plant properties that control $E_{\mathrm{p}}$, such as leaf area index, plant height and unstressed stomatal conductance (see Eqs. 3, 4 and 11). All other factors remaining constant, compensation should be larger for vegetation characterized by large root length to leaf area ratios. These and many of the other plant properties that influence compensation vary with time. However, although the allocation of assimilates to shoots and roots may vary with plant growth stage and also respond to environmental factors, the temporal development of leaf area and root length through the life cycle of a plant is functionally linked (Enquist and Niklas, 2002). Thus, a simpler version of the model which assumes a constant value of $\omega_{c}$ may be quite robust.

The model proposed by Jarvis (1989) is incorporated into the dual-permeability soil water balance and solute transport model MACRO (Larsbo et al., 2005), and as such has been widely applied under field conditions since the early 1990's. Most of these applications have not focused explicitly on the water uptake sub-model, but in those cases where detailed measurements of soil water content have enabled such a test, soil water contents have been found to be accurately simulated (e.g. Jarvis, 1995). The model described by Jarvis (1989) has also recently been included as an option in the HYDRUS-1D simulation model (Šimùnek and Hopmans, 2009). This option was used by Markewitz et al. (2010) who demonstrated an excellent agreement with soil water contents measured to $11 \mathrm{~m}$ depth under an Amazonian rainforest during a 6-yr rainfall exclusion experiment and improved simulations compared to the case without uptake compensation. 

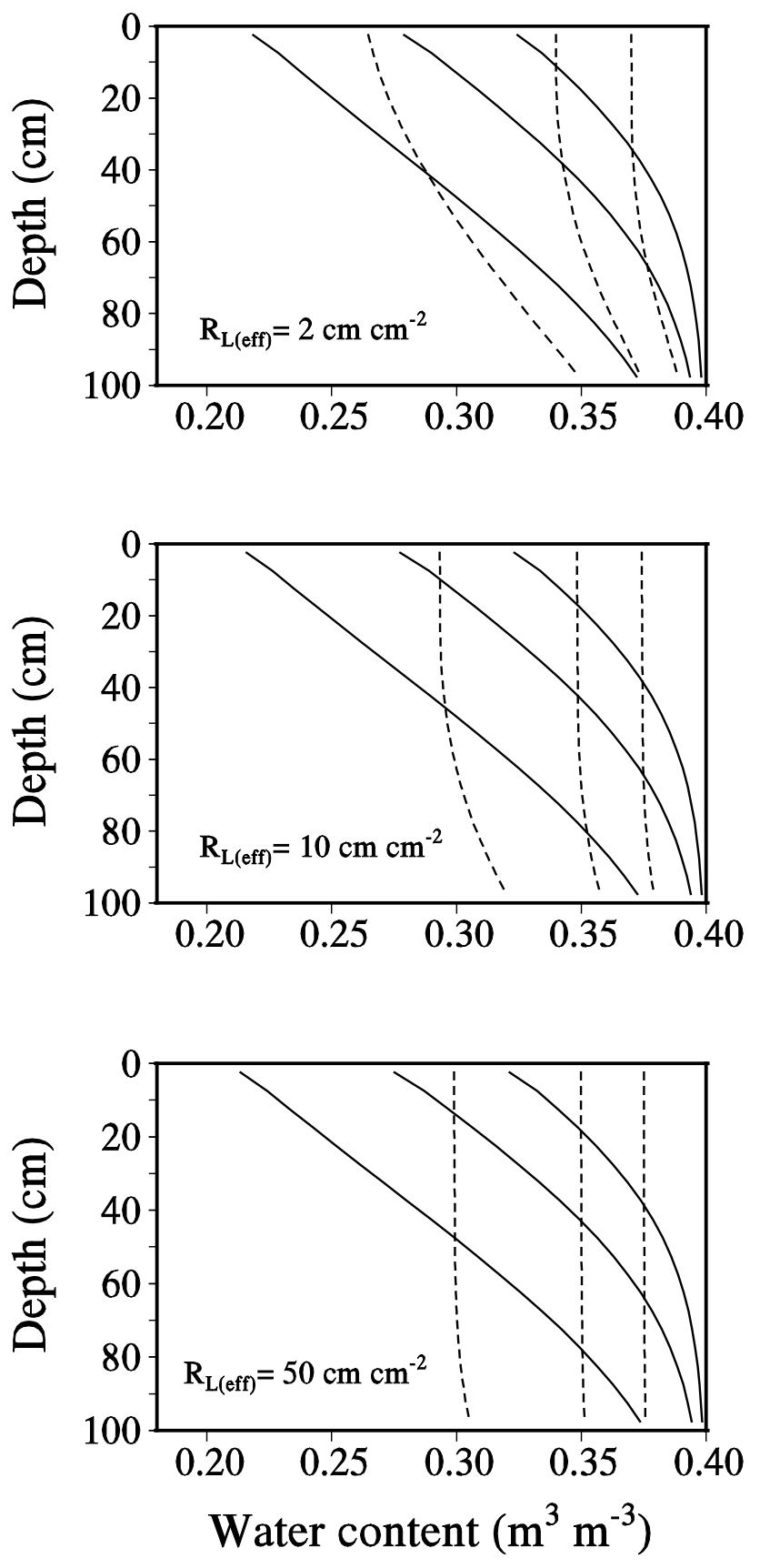

Fig. 2. Water content distributions during dry-down from saturation, simulated with Eqs. (1) to (4) after 5, 10 and 20 days, assuming $M_{0}$ to be given by Eq. (8) (dashed lines) or Eq. (17) (solid lines). Parameter values are given in Table 1 , initial/boundary conditions in the text.

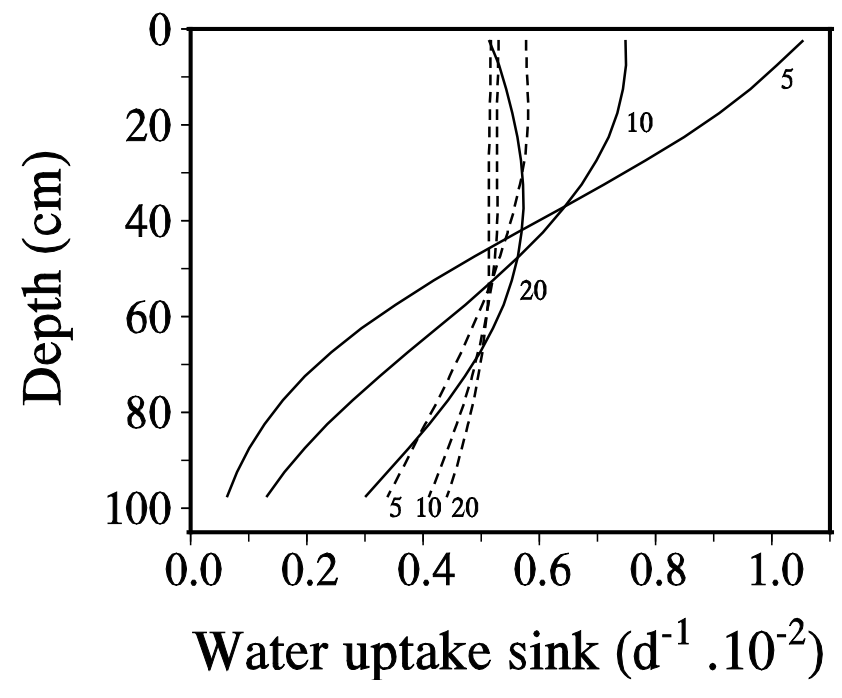

Fig. 3. Water uptake sink during dry-down from saturation, simulated with Eqs. (1) to (4) after 5, 10 and 20 days, assuming $M_{0}$ to be given by Eq. (8) (dashed lines) or Eq. (17) (solid lines), for the case of moderate compensation $\left(R_{L \text { (eff) }}=10 \mathrm{~cm} \mathrm{~cm}^{-2}\right)$. Remaining parameter values are as given in Table 1 , initial/boundary conditions in the text.

\subsection{Example simulations: water uptake under non-stressed conditions}

These simulations illustrate the consequences of the different assumptions concerning the functional form of $M_{0}$ (either Eqs. 8 or 17) for water uptake under non-stressed conditions in the physics-based model given by Eqs. (1) to (4). Simulations are run for a 20-day dry-down period without rainfall, for an initially fully wetted $1 \mathrm{~m}$ deep loamy soil and a transpiration demand of $5 \mathrm{~mm} \mathrm{day}^{-1}$, which is assumed to vary sinusoidally during the day, with a maximum value at midday and a minimum at midnight. For the sake of simplicity, these simulations were run without considering soil water flow. Table 1 lists the parameter values. The root length density was assumed to be distributed according to the equation proposed by Gale and Grigal (1987):

$Y=1-\beta^{z}$

where $Y$ is the cumulative proportion of roots above the depth $z$ (in centimeters) and $\beta$ is an empirical parameter. Three contrasting degrees of compensation ("low", "moderate" and "high") were simulated by varying the effective total root length (see Eqs. 3, 4 and 11). The values chosen $\left(2,10\right.$, and $50 \mathrm{~cm} \mathrm{~cm}^{-2}$, Table 1) were selected to cover most of the range of total live fine root length found among different vegetation types (Jackson et al., 1997), assuming that perhaps up to $10 \%$ of the total fine root length may be effective or active (Faria et al., 2010). With a maximum root depth of $1 \mathrm{~m}$ (Table 1), $1 \%$ of the root length is unaccounted for if $\beta$ is set to 0.955 . This was added to the uppermost 
numerical layer. Matric flux potential, $M$, was calculated from the parameters of the van Genuchten-Mualem model (van Genuchten, 1980) of soil hydraulic properties (see Table 1) using the approximate function derived by de Jong van Lier et al. (2009). With these initial and boundary conditions and parameter values, the plants remained unstressed and actual transpiration equaled the potential rate for the entire 20-day period, with one exception (low compensation and $\mathrm{M}_{0}$ given by Eq. 17), for which actual transpiration was slightly less than the potential rate for the final 2 days of the simulation.

Figure 2a, b, c show the soil water contents simulated by the two model approaches for low, moderate and high degrees of compensation, respectively, on three occasions during the 20-day period (after 5, 10 and 20 days). Figure 3 shows the vertical distribution of the water uptake sink for the case of moderate compensation $\left(R_{L(\text { eff })}=10 \mathrm{~cm} \mathrm{~cm}^{-2}\right)$. These results demonstrate that Eqs. (8) and (17) can give very different water uptake distributions in the soil profile, with the former producing a much more markedly uniform extraction rate with depth. This contrasts with the conclusion drawn by Jarvis (2010) who suggested that the different assumptions concerning $M_{0}$ in the two models would not produce significantly different water uptake distributions under non-stressed conditions. The reason for this apparent contradiction is that the difference between the models is much smaller when compensation is weak (see Fig. 2a-c) and a very low degree of compensation was implicitly assumed in the limited case study presented by Jarvis (2010), significantly lower than that represented by Fig. 2a. Experimental studies of water uptake under field conditions suggest that water uptake closely mirrors the root distribution during the initial dry-down phase (Novák, 1987; Coelho and Or, 1999), which suggests that Eq. (17) produces more realistic simulations than Eq. (8). However, other likely explanations are that the total resistance to uptake is underestimated because plant resistances are ignored and that the effective root length under field conditions is smaller than that assumed here (i.e. less than $10 \%$ of the total root length), because of poor hydraulic contact of roots with soil and its heterogeneous distribution in undisturbed structured soil (e.g. Wang and Smith, 2004; White and Kirkegaard, 2010). If this is the case, the difference between Eqs. (8) and (17) will be much less significant in practice, as suggested by Jarvis (2010).

Unlike Eq. (8), Eq. (17) cannot simulate the phenomenon of hydraulic lift. This is illustrated by Fig. 4 which shows the vertical distribution of the water uptake sink on four occasions (at 06:00, 12:00, 18:00 and 24:00 h) on the fifth day of the simulation. The model represented by Eq. (8) simulates nighttime hydraulic lift in response to the diurnal fluctuation in potential transpiration. As transpiration demand decreases during the night, $M_{0}$ increases (Eq. 8), so $\overline{M_{i}}-M_{0}$ in Eq. (2) becomes negative in the uppermost 50 to $60 \mathrm{~cm}$.

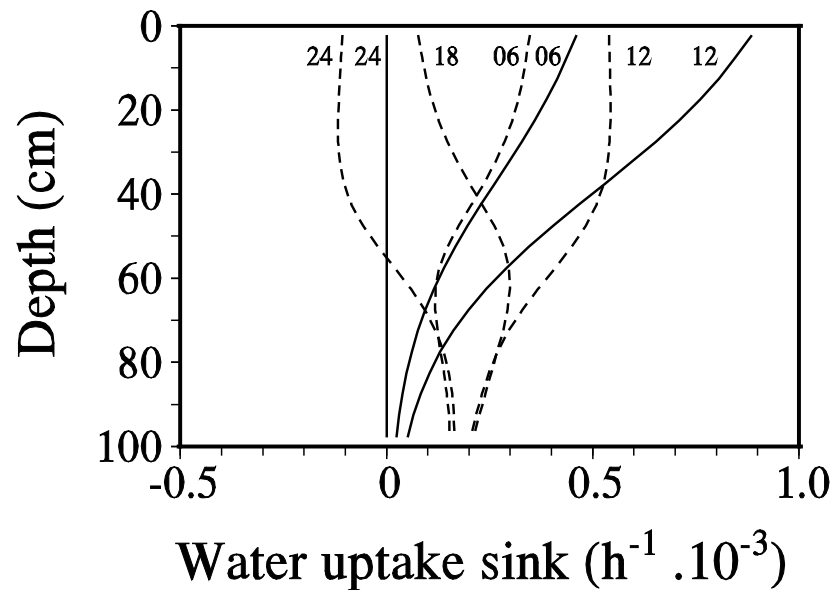

Fig. 4. Diurnal variations in the water uptake sink on day 10 of a 20-day dry-down period from saturation, simulated with equations 1 to 4 , assuming $M_{0}$ to be given by Eq. (8) (dashed lines) or Eq. (17) (solid lines), for the case of moderate compensation $\left(R_{L(\text { eff })}=10 \mathrm{~cm} \mathrm{~cm}^{-2}\right)$. Remaining parameter values are as given in Table 1, initial/boundary conditions in the text.

\section{Case studies}

\subsection{Water uptake by riparian forest}

These simulations illustrate the effects of uptake compensation on the soil water balance in the presence of a shallow water table, by comparing predictions from the physics-based model of compensated uptake represented by Eqs. (1) to (4) and (17) with an uncompensated model based on equation 14. In the latter case, $\alpha$ is assumed to be given by the function adopted in the SiB model (Alton et al., 2009):

$\alpha=\frac{1}{1+e^{2\left(h_{c}-h\right)}}$

where $h$ is in MPa and the critical soil water pressure head, $h_{c}$, is set to $-2 \mathrm{MPa}$.

The simulations are intended to reflect the hydrology of riparian vegetation in Mediterranean or semi-arid/desert climates that meet atmospheric evaporative demand and avoid drought stress with the help of deep roots that exploit groundwater or soil water in the capillary fringe (Zencich et al., 2002; Lamontagne et al., 2005; Cleverly et al., 2006; Gazal et al., 2006). A 100-day dry period was modeled without rain. Soil water flow is calculated by Richards' equation with the soil hydraulic functions given by the Mualem-van Genuchten model (van Genuchten, 1980). The water retention function is given by:

$\bar{\theta}=\left(1+\left(\left|\alpha_{\mathrm{vg}} h\right|\right)^{N}\right)^{\frac{1}{N}-1}$

where the effective water content, $\bar{\theta}$, is given by:

$\bar{\theta}=\frac{\theta-\theta_{\mathrm{r}}}{\theta_{\mathrm{s}}-\theta_{\mathrm{r}}}$ 
where $\theta_{\mathrm{r}}$ is the residual water content $\left(\mathrm{m}^{3} \mathrm{~m}^{-3}\right)$ and $\alpha_{\mathrm{vg}}$ and $N$ are shape parameters. The hydraulic conductivity, $K$, is given by (van Genuchten, 1980):

$K=K_{\mathrm{s}} \overline{\theta^{l}}\left(1-\left(1-\bar{\theta}^{\frac{N}{N-1}}\right)^{1-\frac{1}{N}}\right)^{2}$

where $K_{\mathrm{s}}$ is the saturated hydraulic conductivity and $l$ is a tortuosity factor.

Two contrasting soils are simulated: a sandy soil and the same loamy soil from the previous example (Table 1). It can be noted that the selected parameter values result in a roughly tenfold larger value of the maximum matric flux potential, $M_{\max }$, for the sandy soil compared with the loam (3.22 vs. $0.354 \mathrm{~cm}^{2} \mathrm{~h}^{-1}$ respectively). The bottom boundary condition was given by a pressure potential of zero at the base of the soil profile. The depth of soil profile (and thus the depth to the water table) was varied between 2.5 and $5 \mathrm{~m}$. The initial condition was given as drainage equilibrium with the water table.

A simple approach was used to partition evaporative demand into potential soil evaporation, $E_{\mathrm{p}(\mathrm{s})}$, and transpiration, $E_{\mathrm{p}(\mathrm{t})}$, as a function of canopy leaf area index, LAI:

$E_{\mathrm{p}(\mathrm{s})}=\alpha_{\mathrm{s}} E_{\mathrm{eq}} \tau$

$E_{\mathrm{p}(\mathrm{t})}=\alpha_{t} E_{\mathrm{eq}}(1-\tau)$

where the equilibrium evaporation rate, $E_{\mathrm{eq}}$, was fixed at 0.5 $\mathrm{cm} \mathrm{d}^{-1}$, the Priestley-Taylor co-efficient for soil evaporation $\alpha_{\mathrm{s}}$ was assumed constant at 1.0 , and:

$\tau=e^{-\sigma \mathrm{LAI}}$

where $\sigma$ is set to 0.5 (Table 1). Actual soil evaporation is calculated as the minimum of the potential soil evaporation, $E_{\mathrm{p}(\mathrm{s})}$, and the current maximum supply rate to the soil surface calculated from Darcy's law. Following De Bruin (1983) and Monteith (1995), the Priestley-Taylor coefficient for transpiration, $\alpha_{\mathrm{t}}$, is given as a function of the canopy conductance:

$\alpha_{\mathrm{t}}=\alpha_{\max }\left(1-e^{-\left(\frac{\mathrm{LAI} \cdot g_{\mathrm{gto}}}{0.005}\right)}\right)$

where $\alpha_{\max }$ is set to 1.3 and $g_{\text {sto }}$ is the unstressed stomatal conductance (in $\mathrm{m} \mathrm{s}^{-1}$ ). Based on a summary of literature data, Schulze et al. (1994) reported a mean value of $g_{\text {sto }}$ for sclerophyllous vegetation of $0.0048 \mathrm{~m} \mathrm{~s}^{-1}$. However, a value at the low end of the range reported by Schulze et al. (1994) was selected for the simulations shown here $\left(0.002 \mathrm{~m} \mathrm{~s}^{-1}\right.$, Table 1), since the typical values reported for other vegetation types (temperate grasslands and forests) in Schulze et al. (1994) are up to 2-3 times larger than those given in the more recent review presented by Breuer et al. (2003). Gazal et al. (2006) reported minimum stomatal resistances of the order of $300-500 \mathrm{~s} \mathrm{~m}^{-1}$ for riparian cottonwood forest in
Arizona. A root distribution typifying sclerophyllous woodland and scrub was simulated (see Table 1), with parameter values describing maximum root depth $(2.5 \mathrm{~m})$ and distribution ( $\beta=0.983$ ) set according to the global dataset collated by Schenk and Jackson (2002). Thus, contrasting hydrologic situations are considered in these simulations, from the case where roots are in direct contact with groundwater at $2.5 \mathrm{~m}$ depth, to a case where the water table is located $2.5 \mathrm{~m}$ deeper than the deepest roots. The effective root length $\left(4 \mathrm{~cm} \mathrm{~cm}^{-2}\right.$, Table 1) was estimated from the global database presented by Jackson et al. (1997) as roughly $5 \%$ of the typical live fine root length of sclerophyllous shrubs and trees.

The optimality principle (e.g. Kleidon and Schymanski, 2008; Schymanski et al., 2008; Schaefli et al., 2011) was adopted as a basis for comparing the two models. This was implemented by defining an optimal leaf area as the maximum value of leaf area index LAI that does not result in water stress exceeding a critical level (Woodward, 1987; Kergoat, 1998; Kochendorfer and Ramirez, 2010). The maximum allowable stress was defined as a ratio between total actual and potential transpiration of 0.9 (i.e. actual transpiration for the 100 -day period was $90 \%$ of the potential). This optimization was performed independently for both models for ten fixed water table depths varying between the minimum $(2.5 \mathrm{~m})$ and maximum $(5 \mathrm{~m})$ values considered. A maximum value of LAI was also set $(=4)$ to reflect in a simple way the likelihood of light and/or nutrient limitations on above-ground production when water supply is non-limiting.

Figure $5 \mathrm{a}, \mathrm{b}$ shows the optimal leaf area indices, total transpiration and capillary rise (the latter defined as the flux across the bottom boundary of the profile) simulated as a function of water table depth for the 100-day dry-down period for the loamy and sandy soils respectively. The remaining term in the water balance, soil evaporation, is not shown on these figures, since it amounted to less than $6 \mathrm{~mm}$ in all cases. This is because the soil surface was rather dry even at the start of the simulations. Figure 5a, b show that the uncompensated root water uptake model (Eqs. 14 and 19) is very insensitive both to water table depth and to soil type: irrespective of soil type, the optimal leaf area index is around 1 , the transpiration a little less than $100 \mathrm{~mm}$ and the capillary rise is less than $10 \mathrm{~mm}$, with only small increases in these terms as the water table becomes shallower, approaching the root depth of $2.5 \mathrm{~m}$. In contrast, capillary rise, leaf area index and transpiration show a much stronger sensitivity to water table depth and soil type for the compensated root water uptake model (Eqs. 1 to 4 and 17). The sand, being a more capillary soil, gives rise to a larger capillary rise for any given water table position than the loam, and can therefore support greater leaf area without inducing significant water stress. Figure 5a also demonstrates that models accounting for compensated uptake will not necessarily give larger transpiration rates than uncompensated models (note the results for the loam soil at water table depths $>2.9 \mathrm{~m}$ ). This is because the predictions of the uncompensated model depend 

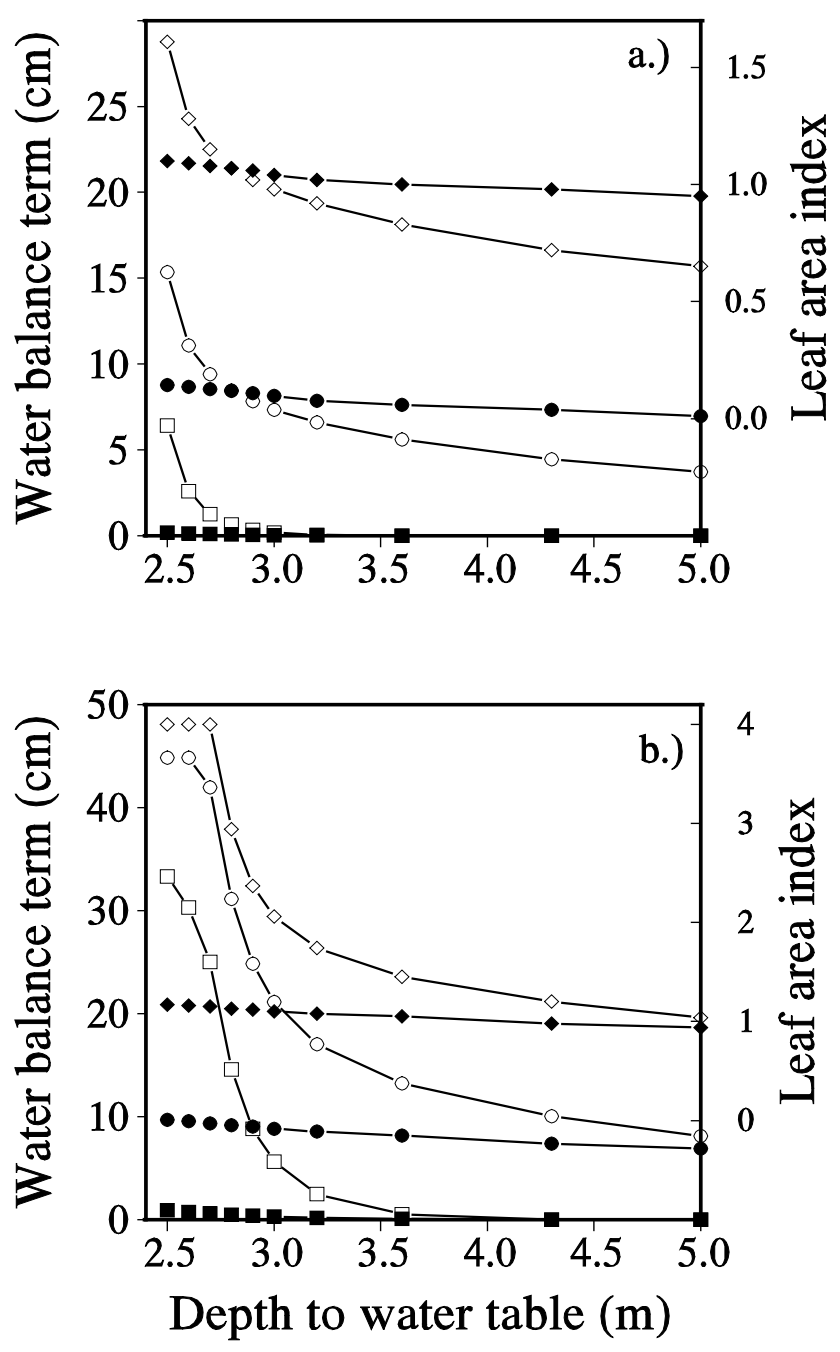

Fig. 5. Leaf area index (diamonds), transpiration (circles) and capillary rise (squares) simulated by compensated (Eqs. 1 to 4 and 17, open symbols) and uncompensated (Eqs. 14 and 19, solid symbols) models as a function of water table depth during a 100-day drydown period for (a) a loamy soil and (b) a sandy soil. Parameter values are given in Table 1, initial/boundary conditions in the text.

on how the empirical function $\alpha$ is defined, which may differ from the physics-based definition in the compensated model.

These simulation results are further illustrated in Fig. 6a, $\mathrm{b}$, which shows the time-course of the water uptake sink term for the sandy soil at a water table depth of $3 \mathrm{~m}$. For the compensated model, the uptake sink becomes progressively dominated by the deeper sparsely rooted layers closest to the water table. Finally, Fig. 7 shows the contrasting water content profiles simulated by the compensated and uncompensated models at the end of the 100-day period. In the latter case, uptake is largely confined to the surface $2 \mathrm{~m}$, and the uppermost $10 \mathrm{~cm}$ of soil dried out to close to wilting point $\left(0.028 \mathrm{~m}^{3} \mathrm{~m}^{-3}\right)$. The subsoil is predicted to be a far more important source of water uptake in the compensated model.
As a kind of qualitative validation test or "reality check", it can be noted that Zencich et al. (2002) and Lamontagne et al. (2005) demonstrated with the help of isotope techniques that during long dry seasons, more than $50 \%$ of the total water uptake of phreatophytic trees and woody shrubs originated from the capillary fringe or from groundwater. In comparison, on the last day of the simulation, ca. $54 \%$ of the water uptake was supplied from the deepest $50 \mathrm{~cm}$ of the root zone (Fig. 6a). In contrast, the uncompensated model predicts that only $2 \%$ of the uptake originates from these layers (Fig. 6b). The simple approach adopted here to determine optimal leaf areas results in a tight coupling between actual transpiration, leaf area index and groundwater depth (Fig. 5a, b), something which has also been observed in such riparian ecosystems (Cleverly et al., 2006; Gazal et al., 2006).

\subsection{Water balance across a continental aridity gradient}

This second case study illustrates the consequences of failing to account for compensatory water uptake for water balances modeled at continental/global scales. Simulations are performed for grassland vegetation at eight locations spanning an east-west aridity gradient across the continental USA (Table 2). Locations at similar latitudes were selected so that potential evapotranspiration was similar at all locations and their climates differed primarily with respect to annual precipitation (Table 2). The temporal distribution of precipitation was also similar, although a summer maximum is somewhat more pronounced at the western end of the aridity gradient. Twenty-year simulations were performed for each site using weather data (precipitation, air temperature, solar radiation) for the period 1971-1990 obtained from SAMSON (http://www7.ncdc.noaa.gov/CDO/cdo) as driving data. Equilibrium evaporation was calculated with the Priestley-Taylor equation. The same models for compensated and uncompensated uptake were used as described in the previous example simulations for riparian forest, but complemented with a simple routine for rainfall interception (Alavi et al., 2001) in which both the canopy storage capacity and the proportion of direct throughfall were given as functions of leaf area index. Leaf area index was assumed to follow a fixed seasonal variation described by a sinusoidal function with a maximum in early summer and a minimum in winter.

A sandy soil was simulated with a unit hydraulic gradient as the bottom boundary condition for a $3 \mathrm{~m}$ deep soil profile. A three-year spin-up period was employed to define the initial condition in the profile. This was found sufficient to ensure that the change of soil water storage at the end of each simulation was negligible. The parameters of the van Genuchten-Mualem model were set according to the HYPRES class pedotransfer functions for a coarse soil (Wösten et al., 1999, Table 1). Vegetation parameters were set to values appropriate for temperate grassland based on literature data collated in global databases (Tables 1 and 3). 
Table 2. Weather stations (SAMSON) used for driving data and nearby catchments (HCDN) with measured discharge/precipitation ratios.

\begin{tabular}{|c|c|c|c|c|c|c|}
\hline \multirow{2}{*}{ Location } & \multirow{2}{*}{$\begin{array}{l}\text { Latitude } \\
\text { Longitude }\end{array}$} & \multirow{2}{*}{$\begin{array}{l}\text { Precipitation } \\
\left(\mathrm{mm} \mathrm{yr}^{-1}\right)\end{array}$} & \multirow{2}{*}{$\begin{array}{l}\text { apotential } \\
\text { evapotranspiration } \\
\left(\mathrm{mm} \mathrm{yr}^{-1}\right)\end{array}$} & \multirow{2}{*}{$\begin{array}{l}{ }^{\mathrm{b}} \text { Aridity } \\
\text { index }\end{array}$} & \multicolumn{2}{|l|}{${ }^{\mathrm{c}} \mathrm{HCDN}$ Catchment } \\
\hline & & & & & Site & $\begin{array}{l}{ }^{\mathrm{d}} \text { Runoff } \\
\text { ratio }\end{array}$ \\
\hline 1.Pueblo, Colorado & $\begin{array}{l}3817^{\circ} \mathrm{N} \\
10431^{\circ} \mathrm{W}\end{array}$ & 279 & 1041 & 3.73 & Conchas River at Variadero & 0.018 \\
\hline 2. Amarillo, Texas & $\begin{array}{l}3514^{\circ} \mathrm{N} \\
10142^{\circ} \mathrm{W}\end{array}$ & 504 & 1085 & 2.15 & Sweetwater Creek nr. Kelton & 0.027 \\
\hline 3. Dodge City, Kansas & $\begin{array}{l}3745^{\circ} \mathrm{N} \\
10101^{\circ} \mathrm{W}\end{array}$ & 561 & 1036 & 1.85 & Crooked Creek, nr. Kye & 0.016 \\
\hline 4. Wichita Falls, Texas & $\begin{array}{l}3358^{\circ} \mathrm{N} \\
9829^{\circ} \mathrm{W}\end{array}$ & 757 & 1138 & 1.50 & $\begin{array}{l}\text { East Fork, Little Wichita River, } \\
\text { nr. Henrietta }\end{array}$ & 0.073 \\
\hline $\begin{array}{l}\text { 5. Oklahoma City, } \\
\text { Oklahoma }\end{array}$ & $\begin{array}{l}3526^{\circ} \mathrm{N} \\
9728^{\circ} \mathrm{W}\end{array}$ & 902 & 1071 & 1.19 & Walnut Creek at Purcell & 0.157 \\
\hline 6. Fort Smith, Arkansas & $\begin{array}{l}3520^{\circ} \mathrm{N} \\
9422^{\circ} \mathrm{W}\end{array}$ & 1075 & 1025 & 0.95 & Lee Creek, nr. van Buren & 0.409 \\
\hline 7. Nashville, Tennessee & $\begin{array}{l}3610^{\circ} \mathrm{N} \\
8647^{\circ} \mathrm{W}\end{array}$ & 1221 & 955 & 0.78 & Sequatchie River, nr. Whitwell & 0.477 \\
\hline $\begin{array}{l}\text { 8. Asheville, North } \\
\text { Carolina }\end{array}$ & $\begin{array}{l}3526^{\circ} \mathrm{N} \\
8232^{\circ} \mathrm{W}\end{array}$ & 1194 & 883 & 0.74 & French Broad River at Asheville & 0.462 \\
\hline
\end{tabular}

a Calculated as 1.3 times the Priestley-Taylor equilibrium evaporation; ${ }^{\mathrm{b}}$ calculated as potential evapotranspiration divided by precipitation (Budyko, 1974); ${ }^{\mathrm{c}}$ http://pubs.usgs.gov/ wri/wri934076/1st_page.html; ${ }^{d}$ calculated as measured stream discharge divided by precipitation.

Table 3. Estimated root depth and distribution and maximum leaf area at the eight locations.

\begin{tabular}{lrrrr}
\hline Location & $\begin{array}{r}\text { Depth containing } \\
95 \% \text { of roots }(\mathrm{m})\end{array}$ & $\begin{array}{r}\text { Root distribution } \\
\text { factor, } \beta\end{array}$ & $\begin{array}{r}\text { a Maximum root } \\
\text { depth (m) }\end{array}$ & $\begin{array}{r}\text { Maximum leaf } \\
\text { area index }\end{array}$ \\
\hline Pueblo, Colorado & 1.30 & 0.9772 & 2.00 & 0.96 \\
Amarillo, Texas & 1.31 & 0.9774 & 2.01 & 1.74 \\
Dodge City, Kansas & 1.21 & 0.9755 & 1.86 & 1.93 \\
Wichita Falls, Texas & 1.05 & 0.9719 & 1.61 & 2.60 \\
Oklahoma City, Oklahoma & 0.87 & 0.9662 & 1.34 & 3.10 \\
Fort Smith, Arkansas & 0.70 & 0.9581 & 1.08 & 3.70 \\
Nashville, Tennessee & 0.58 & 0.9497 & 0.89 & 4.20 \\
Asheville, North Carolina & 0.54 & 0.946 & 0.83 & 4.10 \\
\hline
\end{tabular}

a Defined as the depth containing $99 \%$ of roots.

Based on this literature information, some parameters were assumed constant for all locations, while others varied as a function of climate. The fine root radius $(0.01 \mathrm{~cm}$, Jackson et al., 1997) and the unstressed stomatal conductance of grass $\left(=0.005 \mathrm{~m} \mathrm{~s}^{-1}\right.$, Schulze et al., 1994; Breuer et al., 2003) were set to constant values (Table 1). Both aboveground biomass and leaf area index of temperate grasslands in the continental USA are known to be strongly and more or less linearly dependent on precipitation (e.g. Sala et al., 1988; Lane et al., 2000; Polley et al., 2011). The maximum leaf area index at the eight sites (Table 3 ) was there- fore estimated from a linear regression equation $(=0.00344$ times annual precipitation in $\left.\mathrm{mm} ; R^{2}=0.6, p<0.0001\right)$ fitted to data on temperate grasslands in the USA (Asner et al., 2003; www.daac.ornl.gov). For the sake of simplicity, this maximum leaf area was assumed to occur on Julian day 200 irrespective of site (Table 1). The minimum leaf area index was set to a fixed fraction $(=0.2)$ of the maximum value. Root parameters in the model were estimated from the data collated by Schenk and Jackson (2002) and downloaded from www.daac.ornl.gov. Significant effects of climate on the maximum root depth of temperate grasslands 

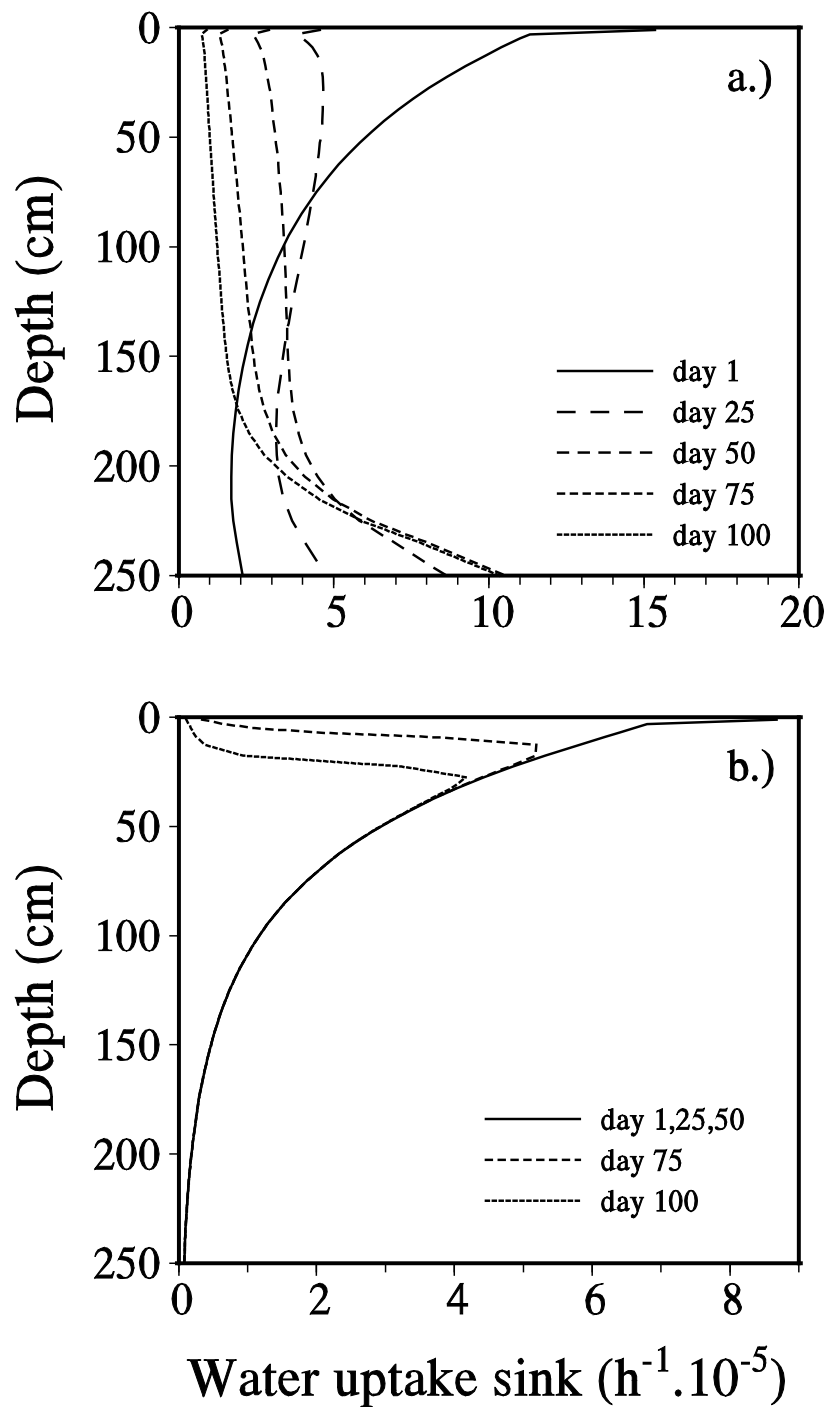

Fig. 6. Water uptake simulated for a sandy soil (Table 1) during a 100-day dry-down period, with the water table at $3 \mathrm{~m}$ depth (a) with uptake compensation (Eqs. 1 to 4 and 17) and (b) without uptake compensation (Eqs. 14 and 19). Initial/boundary conditions are given in the text.

can be detected in this database (Schenk and Jackson, 2002). Despite a large scatter in the data, root depth tends to increase as the climate becomes drier, at least up to an aridity index (Budyko, 1974) of ca. 3. A non-linear regression equation (locally-weighted regression method) was therefore fitted to the data $\left(n=63 ; R^{2}=0.41\right)$ to estimate $95 \%$ root depths for the eight locations (see Table 3 ) as a function of aridity index. Data from tropical grasslands (defined as sites at latitudes less than $25^{\circ} \mathrm{N}$ or S) were excluded from this analysis, as were data from sites where the root depth was deeper than the maximum sampling depth and the latter was $\leq 0.5 \mathrm{~m}$. The root distribution parameter $\beta$ and the maximum root depth (the depth containing $99 \%$ of roots) were then

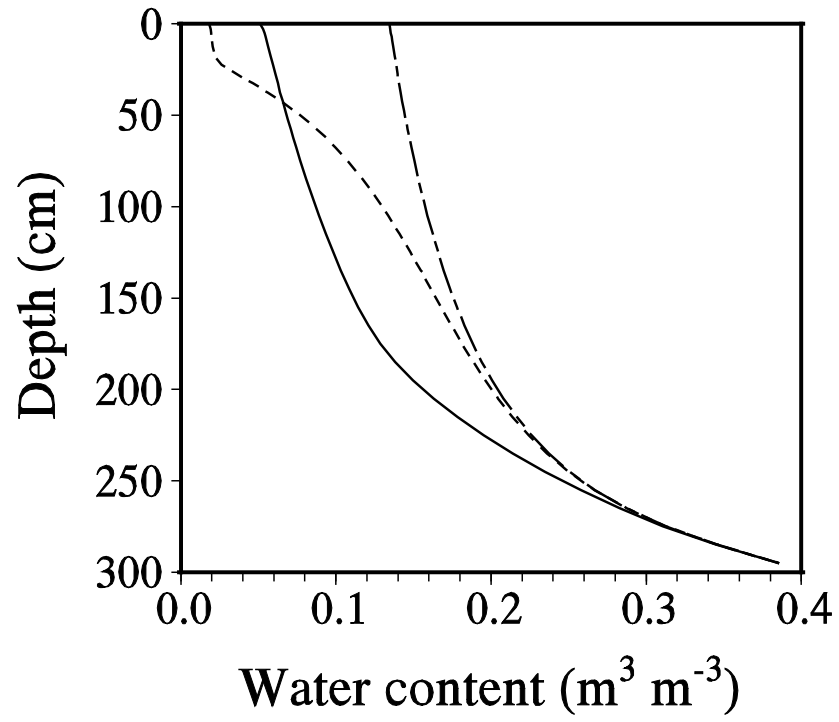

Fig. 7. Water content profiles for a sandy soil (Table 1) after a 100 day dry-down period with a water table at $3 \mathrm{~m}$ depth, simulated with uptake compensation (Eqs. 1 to 4 and 17, solid line) and without (Eqs. 14 and 19, dashed line). The dashed-dotted line shows the initial water contents.

calculated using Eq. (18) (Table 3). In contrast to root depth, no statistically significant trend of root biomass of temperate grasslands $(n=58)$ with long-term precipitation or aridity index could be detected. In a more controlled study, Zhou et al. (2009) also found that root biomass did not vary systematically across an aridity gradient in the southern Great Plains of the USA. Thus, a constant value is assumed for all locations $\left(=56 \mathrm{~cm} \mathrm{~cm}^{-2}\right.$, Table 1$)$, calculated from the mean live fine root biomass $\left(0.95 \mathrm{~kg} \mathrm{~m}^{-2}\right)$ multiplied by a typical specific root length for grasses of $118 \mathrm{~m} \mathrm{~g}^{-1}$ reported by Jackson et al. (1997), assuming that only $5 \%$ of the root length is effective for water uptake. Given the dependence of leaf area on precipitation, a constant root biomass implies that the root/shoot ratio increases as the climate becomes drier, which has also been reported for grasslands in the USA (Zhou et al., 2009) as well as globally (e.g. Mokany et al., 2006). This larger root-shoot ratio enhances water uptake by the compensation mechanism (see Eqs. 3, 4 and 11).

Clearly, there are some uncertainties involved in this parameterization. In the case of the compensated uptake model, the lack of data and process understanding concerning the relationship between effective and total root length probably represents the largest knowledge gap. A simple sensitivity analysis was therefore performed to investigate the likely consequences of these parameter uncertainties on simulated transpiration fluxes. The Oklahoma location (Table 2) was chosen for this analysis, since it was expected that evapotranspiration would be most sensitive to plant parameters controlling water uptake in climates of intermediate aridity (Seneviratne et al., 2010). In dry climates, evapotranspiration 


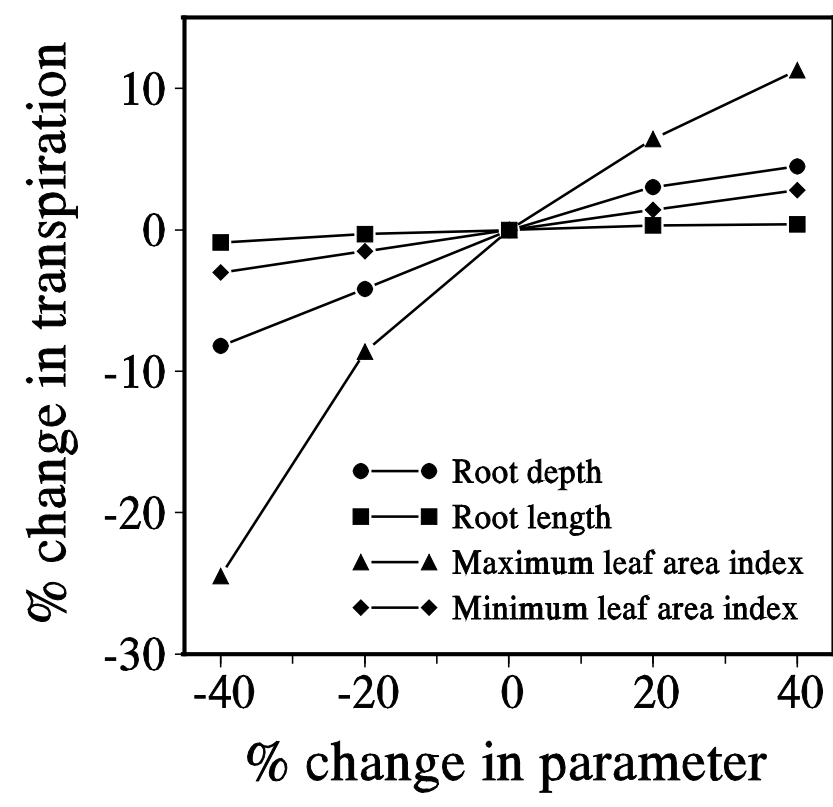

Fig. 8. The sensitivity of simulated total transpiration at Oklahoma City (see Table 2) to changes in the values of parameters controlling root length, root depth and leaf area. The base line parameter set is defined in Tables 1 and 3.

will be limited by precipitation, whereas little stress will occur in wet climates and uptake will be mostly controlled by atmospheric demand. Four parameters (the effective root length, the maximum root depth, and the maximum and minimum leaf area indices) were varied one-at-a-time around their baseline values (Tables 1 and 3 ) by up to $\pm 40 \%$. Figure 8 shows that simulated transpiration was most sensitive to the maximum leaf area, followed by the maximum root depth, while transpiration was insensitive to both the minimum leaf area and especially to the effective root length. This latter result is encouraging because the effective root length is the most uncertain parameter.

The simulated water balances are calculated for virtual locations and, as such, cannot strictly be compared with measurements. However, a simple "reality check" is presented here to confirm that the simulated water balances are at least reasonable. Figure 9 shows a comparison of simulated percolation (as a proportion of precipitation) at the base of the soil profile with catchment runoff ratios (stream discharge divided by precipitation) derived from the USGS HCDN database (http://pubs.usgs.gov/wri/ wri934076/1st_page.html) for the period from 1971 to 1988. Catchments measured close by the weather station locations were selected with, as far as possible, little forest cover (the Tennessee and North Carolina sites, which both had $73 \%$ forest cover, were exceptions). Figure 9 shows an encouraging agreement between simulated and measured runoff, especially considering the mismatch in scales between the model (a single soil profile) and the data (catchments varying from

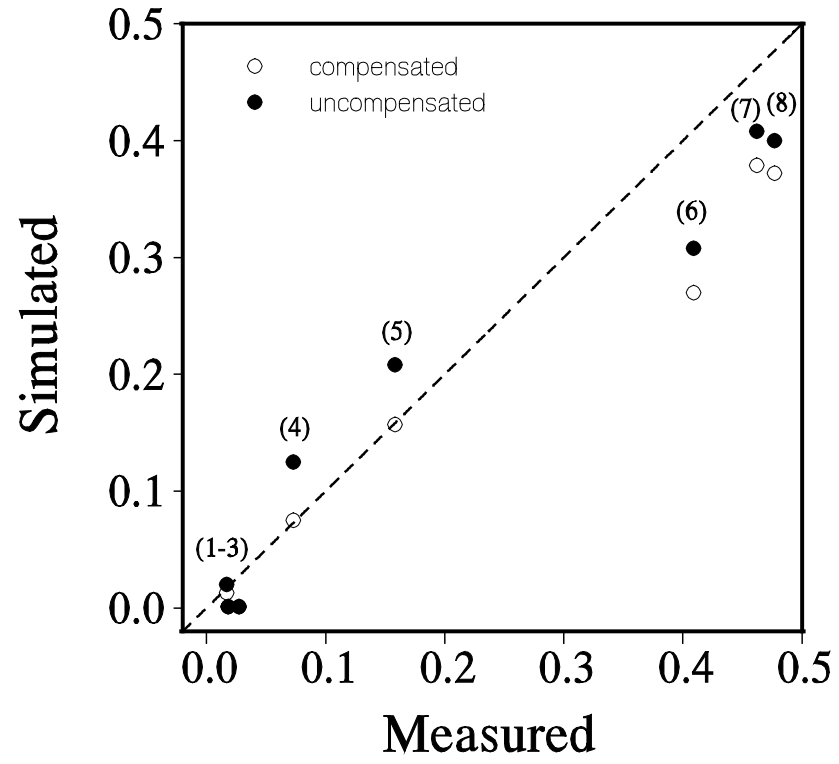

Fig. 9. Comparison of simulated runoff ratio (percolation/precipitation) with measured stream discharge/precipitation ratios (HCD database http://pubs.usgs.gov/wri/wri934076/1st_page. html) (numbers on symbols refer to sites listed in Table 2).

ca. 450 to $3000 \mathrm{~km}^{2}$ in size, with contrasting soil types and vegetation cover). Simulated runoff is generally less than measured in the wetter climates, which is to be expected since the model does not account for fast runoff processes such as surface runoff and preferential flow that short-circuit the plant root zone.

Figure 10 shows a comparison of transpiration and evapotranspiration fluxes simulated by the compensated and uncompensated models. As expected, the difference in total evapotranspiration was negligible in arid climates (aridity index $>$ ca. 1.5 to 2 ), since runoff is negligible and the total evaporation flux equals precipitation. In less arid climates, the compensated model gives ca. 5 to $7 \%$ larger evaporation fluxes, with this difference between models becoming smaller in more humid climates with an aridity index less than 1 (Fig. 10). In principle, these differences in predicted evapotranspiration between models should disappear in very humid climates in which water stress does not occur. It might be considered that differences in total evapotranspiration of this order of magnitude between the two models would, in practice, be overshadowed by parameter error and uncertainty. This would certainly be the case if the uncompensated model gave random error, but the error is systematic (Fig. 10), which implies that a systematic error in other difficult-to-measure model parameter(s), such as the maximum root depth, would be required to compensate for it. This might be the outcome of model calibration if parameters are insufficiently constrained by scarce data (Beven, 1993). 


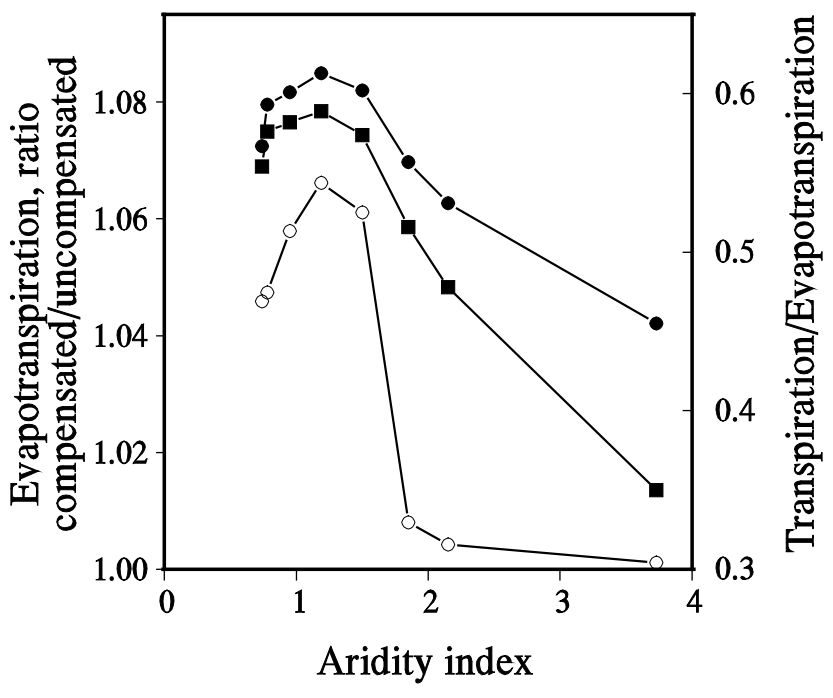

Fig. 10. Transpiration and evapotranspiration simulated by compensated and uncompensated models as a function of the aridity index (defined here as $1.3 \mathrm{x}$ equilibrium evaporation divided by precipitation). Open symbols are the evapotranspiration ratio (compensated/uncompensated; plotted against the left axis); closed symbols (right-hand axis) show the ratio of transpiration to evapotranspiration $($ circles $=$ compensated model, squares $=$ uncompensated model).

In coupled ecological-hydrological models that consider dynamic feedbacks between climate with vegetation (e.g. Neilson 1995; Sitch et al., 2003; Schymanski et al., 2009), the partitioning between transpiration and evaporation will also be critical, since transpiration is tightly coupled with carbon assimilation. Figure 10 shows that the ratio of transpiration to total evaporation is generally larger for the compensated model: the differences are relatively small for humid climates, but become progressively more significant as the climate becomes drier. Interestingly, the ratio of simulated actual to potential transpiration was remarkably constant across the eight sites, varying between 0.84 and 0.92 for the compensated model (with an average value of 0.87 ) and showing no apparent trend with aridity. This result, which is the outcome of "forward" simulations parameterized solely from literature data, suggests that the use of a constant ratio of actual to potential transpiration (c.f. the first case study discussed earlier), may be a very simple and effective way of implementing the optimality principle (e.g. Kleidon and Schymanski, 2008; Schaefli et al., 2011) into global ecohydrological models.

\section{Conclusions}

The simple macroscopic model approaches discussed in this paper provide useful insights into the physical basis of uptake compensation and the plant and soil factors that control it. In particular, it was demonstrated that the degree of compensation is related to soil capillarity and the ratio of to- tal effective root length to potential transpiration, $E_{\mathrm{p}}$. Apart from atmospheric conditions, $E_{\mathrm{p}}$ depends on above-ground plant morphological and physiological factors such as plant height, leaf area and unstressed stomatal conductance. These parsimonious physics-based approaches therefore show great promise to support global modeling exercises since their parameters are, in principle, all measurable. However, more research is clearly needed, for example, to evaluate the effects of model assumptions introduced to make the problem tractable (e.g. the neglect of internal plant resistances), to determine the relationship between total and effective root length and also the most appropriate functional form for $M_{0}$ in Eq. (2). These questions can only be answered by testing alternative model concepts against experimental data. This will not be a straightforward task under field conditions, as the data normally available to validate models (e.g. soil water contents measured as a function of depth and time) may not be sufficient to distinguish errors arising from the description of root water uptake from model and parameter error related to soil hydraulic properties, root distribution, soil water flow and potential evapotranspiration.

The case studies presented here suggest that models that fail to account for compensatory water uptake will introduce error and bias into predictions of eco-hydrological models, both at local scales, for example in relation to site factors such as water table depth and also at global scales in relation to climatic factors. However, it is also important to note that models that only consider the physical basis of compensatory uptake also have their limitations. Biological responses to plant water stress in terms of altered spatial patterns of root growth, activity and turnover do not lend themselves as easily to exact mathematical description, but an ideal model should explicitly consider both the physical basis of root water uptake and the plant response in terms of dynamic root growth linked to both local soil conditions and above-ground assimilation. Such a model would not need to assume "a priori" a given static root distribution, which is one limitation of most widely-used macroscopic water uptake models. Instead, the distribution of root length density would follow from the interactions between soil and atmospheric conditions and the current state of plant development (e.g. Schymanski et al., 2008, 2009). Coupled vegetation-hydrologic models that incorporate such dynamic interactions between climate, hydrologic processes and vegetation are becoming widely used. The illustrative simulations presented here show that, when building models to tackle the complexities of the dynamic eco-hydrological system, it is critically important that submodels of root water uptake are physics-based.

Acknowledgements. I would like to thank Stan Schymanski (Max Planck Inst.), Ryan Teuling (Wageningen University) and Ciaran Harman (University of Illinois) for helpful discussions which led to a more precise and pedagogic description of the model concepts outlined in the paper.

Edited by: M. Weiler 


\section{References}

Alavi, G., Jansson, P.-E., and Hallgren, J.-E.: Interception of a dense spruce forest, performance of a simplified canopy water balance model, Nord. Hydrol., 32, 265-284, 2001.

Alton, P., Fisher, R., Los, S., and Williams, M.: Simulations of global evapotranspiration using semiempirical and mechanistic schemes of plant hydrology, Global Biogeochem. Cy., 23, GB4023, doi:10.1029/2009GB003540, 2009.

Arya, L. M., Blake, G. R., and Farrell, D. A.: A field study of soil water depletion patterns in presence of growing soybean roots. II. Effect of plant growth on soil water pressure and water loss patterns, Soil Sci. Soc. Am. J., 39, 430-436, 1975a.

Arya, L. M., Blake, G. R., and Farrell, D. A.: A field study of soil water depletion patterns in presence of growing soybean roots. III. Rooting characteristics and root extraction of soil water, Soil Sci. Soc. Am. J., 39, 437-444, 1975b.

Asner, G. P., Scurlock, J. M. O., and Hicke, J. A.: Global synthesis of leaf area index observations: implications for ecological and remote sensing studies, Global Ecol. Biogeogr., 12, 191205, 2003.

Benjamin, J. G. and Nielsen, D. C.: Water deficit effects on root distribution of soybean, field pea and chickpea, Field Crop. Res., 97, 248-253, 2006.

Beven, K.: Prophecy, reality and uncertainty in distributed hydrological modeling, Adv. Water Res., 16, 41-51, 1993.

Bodner, G., Loiskandl, W., and Kaul, H.-P.: Cover crop evapotranspiration under semi-arid conditions using FAO dual crop coefficient method with water stress compensation, Agr. Water Manage., 93, 85-98, 2007.

Braud, I., Varado, N., and Olioso, A.: Comparison of root water uptake modules using either the surface energy balance or potential transpiration, J. Hydrol., 301, 267-286, 2005.

Breuer, L., Eckhardt, K., and Frede, H.-G.: Plant parameter values for models in temperate climates, Ecol. Modell., 169, 237-293, 2003.

Budyko, M. I.: Climate and life. Academic Press, Orlando, Florida, 508 pp., 1974.

Cabelguenne, M. and Debaeke, P.: Experimental determination and modeling of the soil water extraction capacities of crops of maize, sunflower, soya bean, sorghum and wheat, Plant Soil, 202, 175-192, 1998.

Caldwell, M. M., Dawson, T. E., and Richards, J. H.: Hydraulic lift: consequences of water efflux from the roots of plants, Oecologia, 113, 151-161, 1998.

Carmi, A., Plaut, Z., and Sinai, M.: Cotton root growth as affected by changes in soil water distribution and their impact on plant tolerance to drought, Irrigation Sci., 13, 177-183, 1993.

Casaroli, D., de Jong van Lier, Q., and Neto, D. D.: Validation of a root water uptake model to estimate transpiration constraints, Agr. Water Manage., 97, 1382-1388, 2010.

Celette, F., Gaudin, R., and Gary, C.: Spatial and temporal changes to the water regime of a Mediterranean vineyard due to the adoption of cover cropping, Eur. J. Agron., 29, 153-162, 2008.

Clausnitzer, V. and Hopmans, J. W.: Simultaneous modeling of transient three-dimensional root growth and soil water flow, Plant Soil, 164, 299-314, 1994.

Cleverly, J. R., Dahm, C. N., Thibault, J. R., McDonnell, D. E., and Allred Coonrod, J. E.: Riparian ecohydrology: regulation of water flux from the ground to the atmosphere in the middle Rio
Grande, New Mexico, Hydrol. Process., 20, 3207-3225, 2006.

Coelho, E. F. and Or, D.: Root distribution and water uptake patterns of corn under surface and subsurface drip irrigation, Plant Soil, 206, 123-136, 1999.

Dawson, T. E.: Hydraulic lift and water use by plants: implications for water balance, performance and plant-plant interactions, Oecologia, 95, 565-574, 1993.

de Bruin, H. A. R.: A model for the Priestley-Taylor parameter $\alpha$, J. Clim. Appl. Meteorol., 22, 572-578, 1983.

de Jong van Lier, Q., Metselaar, K., and van Dam, J. C.: Root water extraction and limiting soil hydraulic conditions estimated by numerical simulation, Vadose Zone J., 5, 1264-1277, 2006.

de Jong van Lier, Q., van Dam, J. C., Metselaar, K., de Jong, R., and Duijnisveld, W. H. M.: Macroscopic root water uptake distribution using a matric flux potential approach, Vadose Zone J., 7, 1065-1078, 2008.

de Jong van Lier, Q., Dourado Neto, D., and Metselaar, K.: Modeling of transpiration reduction in van GenuchtenMualem type soils, Water Resour. Res., 45, W02422, doi:10.1029/2008WR006938, 2009.

Desborough, C. E.: The impact of root weighting on the response of transpiration to moisture stress in land surface schemes, Mon. Weather Rev., 125, 1920-1930, 1997.

Doussin, C.: Soil exploration and resource acquisition by plant roots: an architectural and modelling point of view, Agronomie, 23, 419-431, 2003.

Draye, X., Kim, Y., Lobet, G., and Javaux, M.: Model-assisted integration of physiological and environmental constraints affecting the dynamic and spatial patterns of root water uptake from soils, J. Exp. Bot., 61, 2145-2155, 2010.

El-Maayar, M., Price, D. T., and Chen, J. M.: Simulating daily, monthly and annual water balances in a land surface model using alternative root water uptake schemes, Adv. Water Res., 32, 1444-1459, 2009.

Engels, C., Mollenkopf, M., and Marschner, H.: Effect of drying and rewetting the topsoil on root growth of maize and rape in different soil depths, Z. Pflanzenernähr. Bodenk., 157, 139-144, 1994.

Enquist, B. J. and Niklas, K. J.: Global allocation rules for patterns of biomass partitioning in seed plants, Science, 295, 1517-1520, 2002.

Faria, L. N., Da Rocha, M. G., De Jong van Lier, Q., and Casaroli, D.: A split-pot experiment with sorghum to test a root water uptake partitioning model, Plant Soil, 331, 299-311, 2010.

Feddes, R. A., Kowalik, P., and Zaradny, H.: Simulation of field water use and crop yield, Pudoc, Wageningen, The Netherlands, 189 pp., 1978.

Gale, M. R. and Grigal, D. F.: Vertical root distributions of northern tree species in relation to successional status, Can. J. Forest Res., 17, 829-834, 1987.

Gazal, R. M., Scott, R. L., Goodrich, D. C., and Williams D. G.: Controls on transpiration in a semiarid riparian cottonwood forest, Agr. Forest Meteorol., 137, 56-67, 2006.

Green, S. R. and Clothier, B. E.: Root water uptake by kiwifruit vines following partial wetting of the root zone, Plant Soil, 173, 317-328, 1995.

Jackson, R. B., Mooney, H. A., and Schulze, E.-D.: A global budget for fine root biomass, surface area, and nutrient contents, Proc. Natl. Acad. Sci., 94, 7632-7366, 1997. 
Javaux, M., Schröder, T., Vanderborght, J., and Vereecken, H.: Use of three-dimensional detailed modeling approach for predicting root water uptake, Vadose Zone J., 7, 1079-1088, 2008.

Jarvis, N. J .: A simple empirical model of root water uptake, J. Hydrol., 107, 57-72, 1989.

Jarvis, N. J.: Simulation of soil water dynamics and herbicide persistence in a silt loam soil using the MACRO model, Ecol. Modell., 81, 97-109, 1995.

Jarvis, N. J.: Comment on "Macroscopic root water uptake distribution using a matric flux potential approach", Vadose Zone J., 9, 499-502, 2010.

Jarvis, P. G.: Interpretation of variations in leaf water potential and stomatal conductance found in canopies in field, T. Roy. Soc. London, 273, 593-610, 1976.

Jipp, P. H., Nepstad, D. C., Cassel, D. K., and Reis de Carvalho, C.: Deep soil moisture storage and transpiration in forests and pastures of seasonally-dry Amazonia, Climatic Change, 39, 395412, 1998

Kager, H., Kochler, M., and Stützel, H.: Root growth and dry matter partitioning of cauliflower under drought stress conditions: measurement and simulation, Eur. J. Agron., 20, 379-394, 2004.

Kergoat, L.: A model for hydrological equilibrium of leaf area index on a global scale, J. Hydrol., 212-213, 268-286, 1998.

Kleidon, A. and Heimann, M.: Optimised rooting depth and its impacts on the simulated climate of an atmospheric general circulation model, Geophys. Res. Lett., 25, 345-348, 1998.

Kleidon, A. and Schymanski, S.: Thermodynamics and optimality of the water budget on land: a review, Geophys. Res. Lett., 35, L20404, doi:10.1029/2008GL035393, 2008.

Klepper, B., Taylor, H. M., Huck, M. G., Fiscus, E. L.: Water relations and growth of cotton in drying soil, Agronomy J., 65, 307-310, 1973.

Kochendorfer, J. P. and Ramírez, J. A.: Ecohydrologic controls on vegetation density and evapotranspiration partitioning across the climatic gradients of the central United States, Hydrol. Earth Syst. Sci., 14, 2121-2139, doi:10.5194/hess-14-21212010, 2010.

Lamontagne, S., Cook, P. G., O'Grady, A., and Eamus, D.: Groundwater use by vegetation in a tropical savanna riparian zone (Daly River, Australia), J. Hydrol., 310, 280-293, 2005.

Lane, D. R., Coffin, D. P., and Lauenroth, W. K.: Changes in grassland canopy structure across a precipitation gradient, J. Veg. Sci., 11, 359-368, 2000.

Larsbo, M., Roulier, S., Stenemo, F., Kasteel, R., and Jarvis, N. J.: An improved dual-permeability model of water flow and solute transport in the vadose zone, Vadose Zone J., 4, 398-406, 2005.

Lawrence, P. J. and Chase, T. N.: Climate impacts of making evapotranspiration in the community land model (CLM3) consistent with the simple biosphere model ( $\mathrm{SiB})$, J. Hydrometeorol., 10, 374-394, 2009.

Lee, J.-E., Oliveira, R. S., Dawson, T. E., and Fung, I.: Root functioning modifies seasonal climate, Proc. Natl. Acad. Sci., 102, 17576-17581, 2005.

Markewitz, D., Devine, S., Davidson, E. A., Brando, P., and Nepstad, D. C.: Soil moisture depletion under simulated drought in the Amazon: impacts on deep root uptake, New Phytol., 187, 592-607, 2010

Meyer, W. S., Tan, C. S., Barrs, H. D., and Smith, R. C. G.: Root growth and water uptake by wheat during drying of undisturbed and repacked soil in drainage lysimeters, Aust. J. Agric. Res., 41, 253-265, 1990.

Mokany, K., Raison, R. J., and Prokushkin, A. S.: Critical analysis of root:shoot ratios in terrestrial biomes, Glob. Change Biol., 12, 84-96, 2006.

Monteith, J. L.: Accommodation between transpiring vegetation and the convective boundary layer, J. Hydrol., 166, 251-263, 1995.

Neilson, R. P.: A model for predicting continental-scale vegetation distribution and water balance, Ecol. Appl., 5, 362-386, 1995.

Nnyamah, J. U. and Black, T. A.: Rates and patterns of water uptake in a Douglas-fir forest, Soil Sci. Soc. Am. J., 41, 972-979, 1977.

Novák, V.: Estimation of soil-water extraction patterns by roots, Agr. Water Manage., 12, 271-278, 1987.

Oliveira, R. S., Bezerra, L., Davidson, E. A., Pinto, F., Klink C. A., Nepstad, D. C., and Moreira, A.: Deep root function in soil water dynamics in cerrado savannas of central Brazil, Funct. Ecol., 19, 574-581, 2005.

Paço, T. A., David, T. S., Henriques, M. O., Pereira, J. S., Valente, F., Banza, J., Pereira, F. L., Pinto, C., and David, J. S.: Evapotranspiration from a Mediterranean evergreen oak savannah: the role of trees and pasture, J. Hydrol., 369, 98-106, 2009.

Peek, M. S., Leffler, A. J., Hipps, L., Ivans, S., Ryel, R. J., and Caldwell, M. M.: Root turnover and relocation in the soil profile in response to seasonal soil water variation in a natural stand of Utah juniper (Juniperus osteosperma), Tree Physiol., 26, 14691476, 2006.

Polley, H. W., Phillips, R. L., Frank, A. B., Bradford, J. A., Sims, P. L., Morgan, J. A., and Kiniry, J. R.: Variability in light-use efficiency for gross primary productivity on Great Plains grasslands, Ecosystems, 14, 15-27, 2011.

Sala, O. E., Parton, W. J., Joyce, L. A., and Lauenroth, W. K.: Primary production of the central grassland region of the United States, Ecology, 69, 40-45, 1988.

Seneviratne, S. I., Corti, T., Davin, E. L., Hirschi, M., Jaeger, E. B., Lehner, I., Orlowsky, B., and Teuling A. J.: Investigating soil moisture-climate interactions in a changing climate: a review, Earth-Sci. Rev., 99, 125-161, 2010.

Schaefli, B., Harman, C. J., Sivapalan, M., and Schymanski, S. J.: HESS Opinions: Hydrologic predictions in a changing environment: behavioral modeling, Hydrol. Earth Syst. Sci., 15, 635646, doi:10.5194/hess-15-635-2011, 2011.

Schenk, H.-J. and Jackson, R. B.: The global biogeography of roots, Ecol. Monographs, 72, 311-328, 2002.

Schröder, T., Javaux, M., Vanderborght, J., and Vereecken, H.: Comment on "Root water extraction and limiting soil hydraulic conditions estimated by numerical simulation", Vadose Zone J., 6, 524-526, 2007.

Schulze, E.-D., Kelliher, F. M., Körner, C., Lloyd, J., and Leuning, R.: Relationships among maximum stomatal conductance, ecosystem surface conductance, carbon assimilation rate, and plant nitrogen nutrition: a global ecology scaling exercise, Annual Rev. Ecol. Syst., 25, 629-662, 1994.

Schymanski, S. J., Sivapalan, M., Roderick, M. L., Beringer, J., and Hutley, L. B.: An optimality-based model of the coupled soil moisture and root dynamics, Hydrol. Earth Syst. Sci., 12, 913932, doi:10.5194/hess-12-913-2008, 2008.

Schymanski, S. J., Sivapalan, M., Roderick, M. L., Hutley, L. B., and Beringer, J.: An optimality-based model of the dynamic 
feedbacks between natural vegetation and the water balance, Water Resour. Res., 45, W01412, doi:10.1029/2008WR006841, 2009.

Sharp, R. E. and Davies, W. J.: Root growth and water uptake by maize plants in drying soil, J. Exp. Bot., 36, 1441-1456, 1985.

Šimùnek, J. and Hopmans, J. W.: Modeling compensated root water and nutrient uptake, Ecol. Modell., 220, 505-521, 2009.

Sitch, S., Smith, B., Prentice, I. C., Arneth, A., Bondeau, A., Cramer, W., Kaplan, J. O., Levis, S., Lucht, W., Sykes, M. T., Thonicke, K., and Venevsky, S.: Evaluation of ecosystem dynamics, plant geography and terrestrial carbon cycling in the LPJ dynamic global vegetation model, Glob. Change Biol., 9, 161185,2003

Somma, F., Hopmans, J. W., and Clausnitzer, V.: Transient threedimensional modeling of soil water and solute transport with simultaneous root growth, root water and nutrient uptake, Plant Soil, 202, 281-293, 1998.

Teuling, A. J., Uijlenhoet, R., Hupet, F., and Troch, P. A.: Impact of plant water uptake strategy on soil moisture and evapotranspiration dynamics during drydown, Geophys. Res. Lett., 33, L03401, doi:10.1029/2005GL025019, 2006a.

Teuling, A. J., Seneviratne, S. I., Williams, C., and Troch, P. A.: Observed timescales of evapotranspiration response to soil moisture, Geophys. Res. Lett., 33, L23403, doi:10.1029/2006GL028178, 2006b.

Van Genuchten, M. T.: A closed form equation for predicting the hydraulic conductivity of unsaturated soils, Soil Sci. Soc. Am. J., 44, 892-898, 1980.

Varado, N., Braud, I., and Ross, P. J.: Development and assessment of an efficient vadose zone module solving the 1D Richards' equation and including root extraction by plants, J. Hydrol., 323, 258-275, 2006.

Wan, C., Yilmaz, I., and Sosebee, R. E.: Seasonal soil-water availability influences snakeweed root dynamics, J. Arid Environ., 51, 255-264, 2002.
Wang, E. and Smith, C. J.: Modelling the growth and water uptake function of plant root systems: a review, Australian J. Agric. Res., 55, 501-523, 2004.

White, R. G. and Kirkegaard, J. A.: The distribution and abundance of wheat roots in a dense, structured subsoil - implications for water uptake, Plant, Cell and Environment, 33, 133-148, 2010.

Woodward, F. I.: Climate and plant distribution. Cambridge University Press, Cambridge, UK, 174 pp., 1987.

Wösten, J. H. M., Lilly, A., and Nemes, A.: Development and use of a database of hydraulic properties of European soils, Geoderma, 90, 169-185, 1999.

Wraith, J. M. and Wright, C. K.: Soil water and root growth, HortScience, 33, 951-959, 1998.

Yadav, B. K., Mathur, S., and Siebel, M. A.: Soil moisture dynamics modeling considering the root compensation mechanism for water uptake by plants, J. Hydrol. Eng., 14, 913-922, 2009.

Zencich, S. J., Froend, R. H., Turner, J. V., and Gailitis, V.: Influence of groundwater depth on the seasonal sources of water accessed by Banksia tree species on a shallow, sandy coastal aquifer, Oecologia, 131, 8-19, 2002.

Zeng, X., Dai, Y., Dickinson, R., and Shaikh, M.: The role of root distribution for climate simulation over land, Geophys. Res. Lett., 25, 4533-4536, 1998.

Zhang, H., Morison, J. I. L., and Simmonds, L. P.: Transpiration and water relations of poplar trees growing close to the water table, Tree Physiol., 19, 563-573, 1999.

Zhou, X., Talley, M., and Luo, Y.: Biomass, litter, and soil respiration along a precipitation gradient in Southern Great Plains USA, Ecosystems, 12, 1369-1380, 2009.

Zuo, Q., Shi, J., Li, Y., and Zhang, R.: Root length density and water uptake distributions of winter wheat under sub-irrigation, Plant Soil, 285, 45-55, 2006. 